\title{
DESOGESTREL DOWN-REGULATES PHOX2B AND ITS TARGET GENES IN PROGESTERONE RESPONSIVE NEUROBLASTOMA CELLS
}

Silvia CARDANI ${ }^{\mathrm{a}}$, Simona DI LASCIO ${ }^{\mathrm{a}}$, Debora BELPERIO ${ }^{\mathrm{a}}$, Erika DI BIASE ${ }^{\mathrm{a}}$, Isabella CECCHERINI $^{\mathrm{c}}$, Roberta BENFANTE ${ }^{\mathrm{b}, \mathrm{a}^{*}}$, Diego FORNASARI $^{\mathrm{a}, \mathrm{b}^{*}}$

${ }^{\mathrm{a}}$ Dept. of Medical Biotechnology and Translational Medicine (BIOMETRA), Università degli Studi di Milano, via Vanvitelli 32, 2019 Milan, Italy

${ }^{\mathrm{b}} \mathrm{CNR}$-Neuroscience Institute, via Vanvitelli 32, 20129 Milan, Italy

${ }^{c}$ Laboratorio di Genetica Molecolare, Istituto Giannina Gaslini, Largo G. Gaslini 5, 16148 Genoa, Italy

\section{*Corresponding authors:}

Diego Fornasari, MD, PhD

Dept. of Medical Biotechnology and Translational Medicine (BIOMETRA),

Università degli Studi di Milano

Via Vanvitelli, 32

20129 - Milan (Italy)

Tel: +390250316960

Fax: +3902 50317132

E-mail: diego.fornasari@unimi.it

Benfante Roberta, $\mathrm{PhD}$

CNR- Neuroscience Institute

Via Vanvitelli, 32

20129 - Milan (Italy)

tel: +3902503 16945

Fax: +3902503 17132

E-mail: $\underline{\text { r.benfante@in.cnr.it }}$

Abbreviations: Sp1: Specificity Protein 1; CREB: CAMP Responsive Element Binding Protein; cJun: c-Jun proto-oncogene; Ap2 $\alpha$ : Activator protein 2 alpha; CCHS: Congenital Central Hypoventilation Syndrome; 3-KDG: 3-Ketodesogestrel; PGR: human Progesterone Receptor; DRB: 5,6 dichloro-beta-D-ribofuranosylbenzimidazole 


\begin{abstract}
The paired-like homeobox $2 \mathrm{~B}$ gene $(P H O X 2 B)$ encodes a key transcription factor that plays a role in the development of the autonomic nervous system and the neural structures involved in controlling breathing. In humans, PHOX2B over-expression plays a role in the pathogenesis of tumours arising from the sympathetic nervous system such as neuroblastomas, and heterozygous PHOX2B mutations cause Congenital Central Hypoventilation Syndrome (CCHS), a lifethreatening neurocristopathy characterised by the defective autonomic control of breathing and involving altered $\mathrm{CO}_{2} / \mathrm{H}^{+}$chemosensitivity. The recovery of $\mathrm{CO}_{2} / \mathrm{H}^{+}$chemosensitivity and increased ventilation have been observed in two CCHS patients using the potent contraceptive progestin desogestrel. Given the central role of $P H O X 2 B$ in the pathogenesis of CCHS, and the progesterone-mediated effects observed in the disease, we generated progesterone-responsive neuroblastoma cells, and evaluated the effects of 3-Ketodesogestrel (3-KDG), the biologically active metabolite of desogestrel, on the expression of $P H O X 2 \mathrm{~B}$ and its target genes. Our findings demonstrate that, through progesterone nuclear receptor PR-B, 3-KDG down-regulates $P H O X 2 B$ gene expression, by a post-transcriptional mechanism, and its target genes and open up the possibility that this mechanism may contribute to the positive effects observed in some CCHS patients.
\end{abstract}

Keywords: PHOX2B, Desogestrel, congenital central hypoventilation syndrome, neuroblastoma, progesterone receptor 


\section{INTRODUCTION}

Heterozygous mutations (frameshift mutations and poly-alanine triplet expansions) in the PHOX2B gene, a key transcription factor that plays a role in the development of the autonomic nervous system and the neural structures involved in controlling breathing [1,2], cause Congenital Central Hypoventilation Syndrome (CCHS; MIM\# 209880), a syndrome of autonomic dysfunction that is characterised by life-threatening sleep-related hypoventilation caused by an abnormal ventilatory response to carbon dioxide: children affected by CCHS require ventilatory support during non-REM sleep (tracheostomy or non-invasive ventilation), although a milder degree of hypoventilation may also be present during REM sleep and wakefulness [3-5]. CCHS may also be associated with a spectrum of non-respiratory symptoms and other conditions (cardiac arrhythmias, ocular and endocrinological disorders) that reflect more generalised autonomic nervous system (ANS) dysregulation, including Hirschsprung's disease and tumours of neural crest origin, and we and others have reported that the complexity of clinical phenotypes is influenced by the type of mutation (frameshift mutations vs poly-alanine triplet expansions), the type of translational frame, and gene dosage [6-13]. No pharmacological treatment has yet proved to be effective in improving the disease-related respiratory defects. Recent findings [14] have shown that two CCHS female patients (respectively with +5 and +6 alanine expansions) using the progestin contraceptive desogestrel for contraceptive purposes experienced a partial recovery of chemosensitivity and increased ventilation, thus opening up new prospects for a pharmacological intervention that could at least improve respiratory symptoms. Desogestrel has much greater affinity for progesterone receptors than progesterone itself $[14,15]$.

Progesterone is a steroid that is primarily synthesised in the gonads, adrenal glands and placenta but, as it is also synthesised de novo in the central and peripheral nervous system, can be classified as a neurosteroid. It is well known that progesterone is a powerful respiratory stimulant that may be useful for treating adult apnea, and it has been suggested that it could also be used for the treatment of apnea in pre-term neonates [16-18]. Progesterone exerts its biological effects by binding nuclear or membrane progesterone receptors, and recent data provide evidence that nuclear receptors are important modulators of respiratory control during sleep and chemoreflex sensitivity: adult female mice from which the nuclear receptor has been deleted show more frequent sighs and post-sigh apnea during non-REM sleep, and reduced responses to hypercapnia after chronic progesterone treatment [19]. Although the exact molecular mechanism of the pharmacological effect of desogestrel is unknown, recent evidence indicates that multiple pathways, involving both medullary and supramedullary neurons, may play a role in the ventilatory effects of desogestrel $[15,20]$. It is also worth noting that a number of rodent brain structures (including some expressing 
Phox $2 \mathrm{~b}$ in adulthood) are activated by desogestrel and the same structures may be involved in the recovery observed in the two CCHS patients; however, the contribution of PHOX2B and its mutations to respiratory improvement has not yet been investigated.

Given the central role of the $P H O X 2 B$ gene in the pathogenesis of CCHS and the coexpression of progesterone receptors and $\mathrm{PHOX} 2 \mathrm{~B}$ in neurons that play a role in $\mathrm{CO}_{2}$ chemosensitivity $[21,22]$, the aim of this study was to determine whether treating PHOX2Bexpressing cell lines with the biologically active metabolite of desogestrel, 3-Ketodesogestrel (3KDG) or etonogestrel [23], affects the expression of $P H O X 2 B$ and its target genes. In order to investigate the relationship between progestin and PHOX2B activity further, we generated a stable progestin-responsive SK-N-BE(2)C neuroblastoma cell line. Neuroblastoma is a universally accepted model of neural crest derivative, with most of the molecular features of a sympathetic ganglionic cell, a kind of structure heavily affected in Phox $2 b$ knock-out mice, that likely share a fraction of its PHOX2B-dependent transcriptome with other types of $\mathrm{PHOX}_{2} \mathrm{~B}^{+}$neurons. In this model, our results provide the evidence of a direct molecular link between PHOX2B and Desogestrel. 


\section{MATERIALS AND METHODS}

\section{Cell cultures}

The SK-N-BE(2)C, IMR32 and SH-SYSY human neuroblastoma cell lines, and the MCF7 and T47D breast carcinoma cell lines were grown in RPMI 1640, 100 units/mL penicillin, 100 $\mathrm{mg} / \mathrm{mL}$ streptomycin, $2 \mathrm{mM}$ L-glutamine (LONZA), supplemented with $10 \%$ foetal bovine serum (FBS, Euroclone) at $37^{\circ} \mathrm{C}$ with $5 \% \mathrm{CO}_{2}$. The T47D cell line was maintained in a medium with added human Insulin (Sigma) to a final concentration of $5 \mu \mathrm{g} / \mathrm{mL}$.

To generate SK-N-BE(2)C neuroblastoma cell line stably expressing human progesterone receptors (PGRs), $7.5 \times 10^{5}$ cells were plated in $100 \mathrm{~mm}$ dishes and transfected with $10 \mu \mathrm{g} P G R$ pCDNA 3.1 myc-His plasmid using a FuGene HD (Promega) transfection reagent in a ratio of 1:4 (DNA:FuGene). Forty-eight hours after transfection, the SK-N-BE(2)C cells were diluted 1:10 in $100 \mathrm{~mm}$ dishes and grown under $700 \mu \mathrm{g} / \mathrm{mL}$ geneticin selection (G-418 Sulfate, Gibco), and the individual colonies were transferred to multi-well plates for further propagation. The selected clones were screened for the expression of intracellular progesterone receptor protein by means of a Western blot assay. The stable SK-N-BE(2)C 5.8 and 6.30 clones were maintained under selection by adding geneticin (G-418 Sulfate, Gibco) at a final concentration of $0.4 \mathrm{mg} / \mathrm{mL}$, with selective medium changes every second day. The desogestrel treatments were carried out by adding $1 \mathrm{nM}$ of the active 3- Keto-desogestrel metabolite (3-KDG, USBiological) for the times indicated in the figure legends. Transcript and protein stability were respectively measured by means of treatment with $75 \mu \mathrm{M}$ 5,6 dichloro-beta-D-ribofuranosylbenzimidazole (DRB, Sigma) and $1 \mu \mathrm{g} / \mathrm{mL}$ Cycloheximide (CHX, Sigma) for the times indicated in the figure legend.

\section{Total RNA extraction, reverse transcription and $q P C R$}

To measure $P H O X 2 B$ and $P G R-B$ mRNA expression level, total RNA was extracted using the RNeasy ${ }^{\mathrm{TM}}$ Mini kit or RNA plus Micro kit and accompanying QIAshredder TM (Qiagen, Hilden, Germany) in accordance with the manufacturer's instructions. Five hundred nanograms of RNA were reverse transcribed using the GoScript ${ }^{\mathrm{TM}}$ Reverse Transcriptase kit (Promega), and PHOX2B, $P G R-B$ and $G A P D H$ transcripts were quantitatively analysed using an ABI Prism Thermocycler QuantStudio 5 (Applied Biosystems, CA). The TaqMan® primer and probe assays (Life Technologies, Inc.) were human PHOX2B (ID \#Hs00243679_m1), human PGR (ID \#Hs01556702_m1), and the endogenous control GADPH (ID \#Hs99999905_m1). Each sample was run in triplicate, and the results were calculated using the $2^{-\Delta \mathrm{CT}}$ and the $2^{-\Delta \Delta \mathrm{CT}}$ methods in order to allow the normalisation of each sample to GAPDH and comparisons with the calibrator of each experiment (set to a value of 1) as indicated in the figure legends. 


\section{Transient transfections and Luciferase assays}

To evaluate the $T L X 2$-luc or $D B H$-luc reporter vectors activity, the cells were transiently transfected or co-transfected by means of lipofection using FuGENE HD transfection reagent (Promega) as previously described [24] using $1.7 \times 10^{5}$ SK-N-BE(2)C cells. Twenty-four hours after transfection, the cells were treated with $1 \mathrm{nM}$ of 3-KDG (USBiological) or $3 \mathrm{nM}$ progesterone (Sigma) for the times indicated in the figure legends.

Luciferase was assayed using the Dual Luciferase Reporter Assay System (Promega) in a GloMax Discovery Luminometer (Promega), and the results were analysed as previously described [24]. All of the transfections were performed in triplicate, and each construct was tested in at least three independent experiments using different batches of plasmid preparation. The results are given as mean values \pm standard deviation (SD), and the data were analysed using an unpaired two-tailed Student's $t$ test or one-way ANOVA and GraphPadPrism 5 Software (GraphPad Software, Inc.) as described in the figure legends; $p$ values of $<0.05$ were considered significant.

\section{Plasmid construction}

The hPGR-pCDNA 3.1 myc-His plasmid, containing the human intracellular progesterone receptor and used to generate the stable SK-N-BE(2)C clones, was obtained by re-cloning the region corresponding to the human $P R-A$ encoding sequence (kindly gifted by Angelo Poletti, University of Milan) into the Bam HI sites of the pCDNA 3.1 myc-His vector (InVitrogen). The region encoding the $\mathrm{N}$-terminus of the $P R-B$ isoform was amplified by means of PCR using cDNA extracted from T47D cells and the GC-rich PCR system (Roche Applied Science), and sub-cloned into the Kpn I and BstE II sites of the pCRII vector (InVitrogen). The oligonucleotide sequences were: forward primer, 5'-CGT CAG ACT GAG CTG AAG GCA AAG- 3'; and reverse primer, 5' GGT GGA TCT TCG GGA AGT TCG GG- 3'. In order to obtain the full-length hPGR-pCDNA 3.1 myc-His construct, the $5^{\prime} P R-B$ fragment was cloned upstream of the $h P R-A$ fragment in the $h P R$-A-pCDNA 3.1 myc-His plasmid, after double enzymatic digestion with Kpn I/Pf1M I restriction enzymes.

The TLX2 (-1185bp) and DBH promoter constructs, used to evaluate the effect of desogestrel on the transcription activity of PHOX2B target genes, have been previously described [25,26]. The progesterone responsive $M M T V$ promoter reporter construct contained the murine mammary tumour virus long terminal repeat (MMTV LTR) inside the pGL3-basic vector (Promega). 
All of the constructs were checked by means of restriction analysis and partial sequencing of both strands. All of the enzymes used for the cloning were purchased from New England Biolabs.

\section{Protein preparation and Western Blot analyses}

For evaluating the effect of desogestrel on PHOX2B and its target genes protein level, total protein extract was prepared from SK-N-BE(2)C cells and the 5.8 and 6.30 clones stably overexpressing PGR using the freeze and thaw method, and was analysed by means of Western blotting as previously described [27]. Table S1 shows the primary and secondary antibodies used.

After appropriate washes, the bands were revealed using Super Signal West Dura (Thermo Fisher Scientific), for the secondary antibodies conjugated with horseradish peroxidase, or the Odyssey CLx Infrared Imaging System for infrared-conjugated IgG IRDye (LI-COR Bioscience). A standard molecular weight (PageRuler ${ }^{\mathrm{TM}}$ Broad Range Unstained Protein Ladder, Thermo-Fisher Scientific and Prestained Protein SHARPMASST ${ }^{\mathrm{M}}$ VII, EuroClone) was loaded in parallel. Densitometric analysis of the obtained signals was carried out using NIH ImageJ 1.61/fat, or Image Studio (LICOR Biosciences) software, and the results are shown as the mean values \pm standard deviation (SD) of at least three independent experiments.

The statistical analyses were made using ANOVA or an unpaired two-tailed Student's $t$ test and GraphPad Prism 5 Software (GraphPad Software, Inc.) as indicated in the figure legends. P values of $<0.05$ were considered significant. 


\section{RESULTS}

\section{Identification of a cell model to study the effect of 3-KDG on PHOX2B}

In order to investigate the mechanism of action of the desogestrel and whether it can affect the expression or activity of PHOX2B and some relevant PHOX2B target genes, we carried out preliminary experiments using the T47D human breast adenocarcinoma cell line, because it has the advantage of expressing intracellular and membrane-associated progesterone receptors, but lacks $P H O X 2 B$ expression. The preliminary experimental evidence obtained by co-transfecting $P H O X 2 B$ cDNA and the TLX2-luc PHOX2B target gene promoter into the T47D cells showed that 3-KDG (the active metabolite of desogestrel) up-regulates the transcription of the $T L X 2$ promoter reporter vector, an effect that is mainly mediated by the intracellular progesterone receptor PR-B (data not shown).

This interesting finding and the notion that neurons that play a central role in $\mathrm{CO}_{2}$ chemosensitivity co-express progesterone receptors and PHOX2B [21,22] prompted us to study the effect of desogestrel on the PHOX2B pathway in a cell model whose cellular background is more closely associated with the physiological PHOX2B environment also in terms of co-activators and co-repressors. To this end, we used real-time PCR to characterise PHOX2B expression (Fig. S1A, grey bars) and progesterone receptor (PGR, the main receptor mediating 3-KDG activities; see Fig. S1A, black bars) in various neuroblastoma cell lines. The IMR32, SK-N-BE(2)C and SH-SY5Y cell lines showed $P H O X 2 B$ expression, but only IMR32 and SK-NBE(2)C also expressed $P G R$, albeit at a level that was 30,000 and 200,000 times lower than its expression in the T47D cell line (Fig. S1A, black bar). Despite their PGR expression, these cell lines were not responsive to progesterone or 3KDG treatment, as confirmed by transient transfection with the PGR-responsive reporter construct MMTV-luc (Fig. S1B, left bars), due to the absence of the PGR protein (Fig. 1A, lanes 1 and 2), but they could be made responsive by transiently co-transfecting the PGR expression vector (Fig. S1B, white striped and cross-hatched bars $v s$ white empty bar). One possibility of the observed loss of progesterone receptor is that neuroblastoma cells express alternatively spliced PGR mRNA variants that give rise to PGR that miss functional domains and make them undetectable by the antibodies used in this study, as already described [28]. Consequently, although the IMR32 cell line expressed higher basal $P H O X 2 B$ and $P G R$ transcript levels than SK-N-BE(2)C (Fig. S1A), we decided to use SK-N-BE(2)C because of its greater capacity for transfection.

\section{3-KDG reduces the expression of $\mathrm{PHOX} 2 \mathrm{~B}$ and of its target genes}

Western blot and densitometric analyses of SK-N-BE(2)C cells transiently transfected with $P G R$ cDNA (hPGR-pcDNA3.1 myc-His) (Fig. 1A, lanes 3 and 4) or pCDNA3 control vector (Fig. 
1A, lanes 1 and 2) and treated with $1 \mathrm{nM}$ of 3-KDG for 48 hours (Fig. 1A, lanes 2 and 4) showed that PHOX2B protein levels were significantly reduced 3-fold in the cells transfected with $\mathrm{h} P G R$ and treated with 3-KDG in comparison with untreated cells (Fig. 1B, white striped bar vs white bar), whereas no significant effect was observed in the cells transfected with the control vector (Fig. $1 \mathrm{~B}$, striped $v s$ plain black bars), thus confirming that 3-KDG has a direct effect on the expression of PHOX2B protein in this cell line. Similarly, the PHOX2B mutant protein carrying one of the most frequent poly-alanine expansion (+7) observed in CCHS was down-regulated upon treatment with 3-KDG (data not shown).

The down-regulation of PHOX2B protein expression after 3-KDG treatment affects the promoter activity of two known PHOX2B target genes, T-cell leukaemia homeobox 2 (TLX2), and dopamine beta-hydroxylase $(D B H)$, both expressed in the SK-N-BE(2)C cell line. Figures $1 \mathrm{C}$ and 1D respectively show a significant 8- and 5-fold decrease in luciferase activity in the cells cotransfected with $\mathrm{h} P G R$ and the $T L X 2$-luc or $D B H$-luc reporter vectors and treated with 3-KDG (white striped bars $v s$ white empty bars). Progesterone had a slightly less efficient but still significant effect (Fig. 1C and 1D, white cross-hatched bars $v s$ white empty bars), as it led to a 4fold and 2-fold reduction in TLX2 and $D B H$ promoter activity. The control cells transfected with luciferase promoter-less reporter constructs pGL3b (vs TLX2-luc) and pGL4b (vs DBH-luc) did not show any significant reduction induced by progestin treatment (Fig. 1C and 1D, striped and crosshatched $v s$ empty grey bars), thus confirming the consistency of the effect of 3-KDG on the two PHOX2B target genes, and suggesting that this reduction may be due to decreased PHOX2B protein availability.

\section{3-KDG down-regulates endogenous PHOX2B protein and target genes in stable progestin- responsive SK-N-BE(2)C cells}

In order to investigate the relationship between progestin and PHOX2B activity further, we generated a stable progestin-responsive SK-N-BE(2)C neuroblastoma cell line that allowed us to avoid the limiting step of the transient $P G R$ transfection (Fig. S2A). The $P G R$ expressing vector used for the stable transfection encodes the two isoforms of intracellular progesterone receptors: the full-length B isoform (PR-B) and the N-terminal truncated isoform (PR-A). Two clones, that had different relative expression levels of the PR-A and PR-B isoforms and named 5.8 and 6.30, were chosen for further analyses (Fig.S2A).

Figure 1A showed that 3-KDG treatment reduced PHOX2B protein levels in SK-N-BE(2)C cells transiently transfected with $P G R$. In order to investigate the mechanism underlying this reduction further and analyse the possible effect of 3-KDG on the PHOX2B pathway, the stable 
SK-N-BE(2)C clones 5.8 and 6.30 were treated with $1 \mathrm{nM} 3-\mathrm{KDG}$ for 8,24 and 48 hours, and the endogenous level of PHOX2B and of some known PHOX2B target genes was evaluated (Fig. 2 and Fig.3). Western blotting (Fig. 2A) and quantification analyses (Fig. 2B) showed that treatment significantly reduced the level of PHOX2B protein in both clones (Fig 2B, grey and white striped bars $v s$ grey and white empty bars) in comparison with the native SK-N-BE(2)C cells used as controls (Fig 2B, black striped and empty bars), albeit with different kinetics between clones. PHOX2B protein level decreased more rapidly in clone 5.8 than in clone 6.30 (Fig 2A, lanes 6-8 vs lanes 10-12), as it was $35 \%$ in clone 5.8 and $90 \%$ in clone 6.30 after eight hours treatment (Fig. 2B, grey $v s$ white striped bars).

We then investigated whether a reduced PHOX2B protein level could affect the expression of some of its already known target genes, $D B H$ and TFAP2A $(A p 2 \alpha)$. As shown in Figure $3 \mathrm{~A}$, as in the case of $\mathrm{PHOX} 2 \mathrm{~B}$, a significant reduction in proteins level at each time point was observed in clone 5.8 (Fig. 3A, lanes 6-8 vs lane 5), in comparison with the treated native cells (Fig. 3A, lanes 2-4 vs lane 1). In particular, after 48 hours 3-KDG treatment DBH was almost undetectable (Fig. $3 \mathrm{~B}$, grey striped bar), whereas TFAP2A was reduced by $95 \%$ only after eight hours (Fig. 3C, grey bars). DBH and AP2 $\alpha$ levels were also reduced in clone 6.30 (Fig. 3B and C, white bars), but to a lesser extent, which led us to hypothesise that the amount of PR-B may affect the expression of these genes differently.

For control purposes, we analysed the expression of proteins that are not direct PHOX2B target genes, such as SP1, CREB and c-JUN (Fig. S3A). There was no significant change in their expression in either of the clones (Fig. S3B to D) or in the control cells, thus confirming the direct effect of desogestrel on PHOX2B expression and/or activity.

In conclusion, our findings demonstrated that 3-KDG directly affects PHOX2B and its target genes by reducing their expression, thus indicating that it has a specific effect on the PHOX2B pathway.

\section{3-KDG partially affects $P H O X 2 B$ mRNA degradation}

In order to investigate the mechanism underlying these effects further, we tested whether the decrease in protein level in clone 5.8 (which showed the most rapid kinetic reduction in PHOX2B protein) was due to reduced transcription or a post-transcriptional level mechanism.

Quantitative PCR analysis of PHOX2B mRNA expression level (Fig. 4A) in SK-N-BE(2)C clone 5.8 and native SK-N-BE(2)C cells treated with $1 \mathrm{nM} 3-\mathrm{KDG}$ for eight, 24 and 48 hours showed that 3-KDG significantly reduced $P H O X 2 B$ mRNA level by 50\%, (Fig. 4A grey bars) and, unlike the protein, which showed a significant reduction of up to $10 \%$ (Fig. 2A), this was maintained during 
the following 48 hours of treatment. No change in the level of mRNA was observed in the native SK-N-BE(2)C cells (Fig 4A, black bars). As shown in Figure 4B (grey bars), PHOX2B mRNA levels were reduced after as little as two hours of treatment, thus supporting the hypothesis that the reduction in PHOX2B protein was partially due to a reduction in mRNA, which may occur because of reduced transcription or reduced transcript stability.

In order to clarify this, we measured the stability of $P H O X 2 B$ mRNA in clone 5.8, by determining its decay after using the RNA pol II inhibitor DRB to inhibit transcription in the presence and absence of 3-KDG treatment (Fig. 4C). Before adding DRB, the cells were pre-treated for 24 hours with $3-\mathrm{KDG}$ or vehicle alone (Fig. 4C). The level of $P H O X 2 B$ mRNA was reduced by $50 \%$ in approximately one hour regardless of the presence (Fig. 4C, solid line) or absence of 3KDG (Fig. 4C dashed line) but, after two hours, it became significantly different because the mRNA was no longer degraded in the absence of 3-KDG (Fig. 4C). This was not due to the induction of transcription of the factor required to degrade $P H O X 2 B$ mRNA by $3-K D G$ because the same result was obtained when 3-KDG was added to DRB (Fig. 4D).

These findings suggest that 3-KDG partially affects $P H O X 2 B$ mRNA stability, and indicate that the $50 \%$ reduction in mRNA was due to greater degradation in the treated sample.

\section{3-KDG does not affect PHOX2B protein stability}

The reduction in $P H O X 2 B$ mRNA levels in experiments in Figures $4 \mathrm{~A}$ and $4 \mathrm{~B}$ does not totally explain the drastic reduction in protein levels in clone 5.8 after 3-KDG treatment (Fig. 2A). In order to investigate the underlying mechanism further, we tested whether 3-KDG also affects PHOX2B protein stability by pre-treating SK-N-BE(2)C clone 5.8 cells with $1 \mu \mathrm{g} / \mathrm{mL}$ cycloheximide (CHX) for one hour, followed by the addition of 3-KDG or DMSO for different times (Fig. 5A), and found no difference in the PHOX2B degradation rate (Fig. 5B, dashed line vs

solid line). Pre-treatment with 3-KDG before adding CHX confirmed that 3-KDG does not induce a factor acting on the degradation of PHOX2B protein.

In conclusion, our findings demonstrated that the effects of 3-KDG on PHOX2B are mediated by increased PHOX2B mRNA degradation (Figs. 4C and D). As the drastic reduction in PHOX2B protein cannot be exclusively attributed to increased protein degradation, we hypothesise that 3-KDG reduces PHOX2B protein by also blocking its translation. 


\section{DISCUSSION}

The findings of this study demonstrate that the biologically active metabolite of desogestrel, 3-KDG, modulates $P H O X 2 B$ gene expression via progesterone nuclear receptor PR-B. Treatment with 3-KDG decreased both $P H O X 2 B$ mRNA and protein levels as a result of an increased mRNA degradation rate and possibly concomitant translation inhibition. Apparently, the increase in mRNA degradation rate and inhibition of translation do not require the synthesis of new molecules, and so the molecular factor(s) involved in the two processes remain to be identified and further investigated. Moreover, PHOX2B protein down-regulation is paralleled by a decrease in two of its well known target genes (DBH and TFAP2A), whereas other genes not regulated by PHOX2B are not affected.

Transcription block experiments showed that the kinetics of $P H O X 2 B$ mRNA degradation is biphasic: almost one half is rapidly degraded in one hour but, after that, the degradation slows and there is no further decrease in mRNA level, thus suggesting the existence of two PHOX2B mRNA pools. Our findings indicate that 3-KDG increases the rate of $P H O X 2 B$ mRNA degradation, and in particular that of the more stable pool of mRNAs. Given that the $P H O X 2 B$ 3' untranslated region (3'UTR), and the microRNAs (miRNAs) targeting it are important for the post-transcriptional regulation of the $P H O X 2 B$ gene, a possibility is that various isoforms of different $3^{\prime}$ UTR lengths are synthesised and have distinct properties and different degradation rates [29]. However, mRNA does not completely disappear and is maintained at a certain level by means of compensatory transcriptional up-regulation. As we observed very little induction of the $P H O X 2 B$ promoter reporter construct (data not shown), we cannot exclude the possibility that the degradation induces a more general synthesis [30]. The different steady-state levels of PHOX2B protein at different time points of treatment and in two stable clones differently expressing progesterone receptors influence the degree of down-regulation of PHOX2B target genes in a gene specific manner. A slight decrease in PHOX2B is not sufficient to down-regulate all PHOX2B target genes, and it has been previously reported that the partial silencing of $P H O X 2 B$ only slightly affects PHOX2B target gene expression [31]. Interestingly, progesterone induces the up-regulation of tyrosine hydroxylase, a well-known PHOX2B target gene, in the SK-N-SH neuroblastoma cell line (which is negative for $P H O X 2 B$ and expresses very low levels of $P H O X 2 A)$ and in the noradrenergic CAD cell line (which expresses higher levels of $P H O X 2 A$ than $P H O X 2 B$ ), thus suggesting that PHOX2B and the cellular context play a critical role in determining positive or negative progesterone-mediated effects [32].

Unlike what has been observed in neuroblastoma cell lines in which $P H O X 2 B$ overexpression plays a pathogenic role, the respiratory and autonomic symptoms of CCHS patients, and 
their predisposition to Hirschsprung's disease and intestinal developmental and functional defects, are due to $P H O X 2 B$ haploinsufficiency [12,33]. In this perspective, the positive effects of desogestrel on ventilation and chemosensitivity observed in two CCHS patients [14,15] are somewhat unexpected because, at molecular level, 3-KDG decreases $P H O X 2 B$ expression. However, in vivo findings argue against the idea that CCHS is due to a pure loss-of-function mechanism, and it is likely that toxic functions gained by mutant proteins also contribute to the respiratory defects [34-39]. In this light, as we observed that PHOX2B mutant protein levels decrease similarly to those of its wild-type counterpart after 3-KDG treatment (data not shown), the beneficial effect of decreasing the level of the mutant PHOX2B may clinically compensate for the potential pathogenic effect of insufficient PHOX2B expression, especially after birth when the differentiation of a number of $\mathrm{PHOX}_{2} \mathrm{~B}^{+}$cell types and autonomic nervous system components such as the enteric nervous system (ENS) has already occurred, at least in patients carrying mild PHOX2B polyAla expansions. It is worth noting that the role of Phox $2 b$ and its mutations has been widely investigated during embryonic development, but their exact role in adulthood is still unclear. Phox $2 b$ gene expression persists in various structures in adult rats and human $[21,40]$, and various findings indicate that it plays a role in maintaining the function of noradrenergic neurons in the adult [41]. Recent studies have also shown residual cardiorespiratory responses in prevalently younger CCHS patients, thus suggesting age-dependent mechanisms such as the developmental reconfiguration of respiratory circuits or the continuing loss of vulnerable cell populations within them due to the expression of an altered PHOX2B transcription factor [42]. In mouse models of CCHS, the development of the retrotrapezoid nucleus (RTN), which expresses Phox $2 b$, is particularly vulnerable to different Phox $2 b$ mutations (frameshift mutations and poly-alanine triplet expansions) that cause $\mathrm{CCHS}$ in humans [34,38,39], and dysfunctioning $\mathrm{CO}_{2} / \mathrm{H}^{+}$ chemosensitive/Phox 2 b-positive neurons in the RTN/pFRG is generally thought to play a critical role in perinatal respiratory control in rodents [43]. However, the fact that mice can survive the selective genetic deletion of the RTN PHOX2B-positive neurons and the loss of breathing stimulation by $\mathrm{CO}_{2}$ suggests that the neurological basis of CCHS is not confined to the absence of the RTN and that compensatory mechanisms may partially restore $\mathrm{CO}_{2}$ sensitivity [36]. Other structures, including some expressing Phox $2 b$ in adulthood, are grossly unaltered in Phox $2 b$ mutant mice (and reasonably in humans), and may be involved in the recovery of the two CCHS patients. One putative structure is the nucleus of the solitary tract (NTS), which expresses Phox $2 b$ in adult rats, is not affected by Phox $2 b$ poly-alanine mutations, and contains neurons that are inhibited by hypoxia but whose activity is restored by progesterone administration [34,44-46]. Consistently, neurons in the commissural part of the NTS are activated by 3-KDG [15,20]. C1 neurons may also 
be involved in the recovery of the two CCHS patients as PHOX2B has been identified in selected populations of $\mathrm{TH}$-expressing neurons in adult rats, including the $\mathrm{C} 1$ neurons [44] that regulate the breathing network at multiple levels [47,48]. It has also been shown that 3-KDG activates catecholaminergic neurons in the ventrolateral medullary reticular nucleus [15].

In conclusion, although our results are based on an in vitro system such as neuroblastoma cell lines, the findings of this study provide the evidence of a direct molecular link between PHOX2B and Desogestrel by showing that 3-KDG down-regulates the expression of $P H O X 2 B$ and its target genes and open up the possibility that the down-regulation of PHOX2B and mutant proteins may contribute to the recovered chemosensitivity and increased ventilation observed in the two CCHS patients taking desogestrel. However, further research is needed to evaluate the usefulness of pharmacological approaches targeting $P H O X 2 B$ and possibly attenuating the deleterious effects of $P H O X 2 B$ mutations in CCHS patients. 


\section{ACKNOWLEDGEMENTS}

This study was supported by the Telethon Foundation [Grant No. GGP13055] to D.F., and the Associazione Italiana per la Sindrome da Ipoventilazione Centrale Congenita (A.I.S.I.C.C.). We are grateful to A.I.S.I.C.C. and all CCHS patients and their families. We would like to thank Kevin Smart for his help in preparing the manuscript.

\section{CONFLICT OF INTEREST}

The authors declare that they have no conflicts of interest with the contents of this article. 


\section{REFERENCES}

[1] A. Pattyn, X. Morin, H. Cremer, C. Goridis, J.F. Brunet, The homeobox gene Phox2b is essential for the development of autonomic neural crest derivatives, Nature 399 (1999) 366370.

[2] A. Pattyn, M. Hirsch, C. Goridis, J.F. Brunet, Control of hindbrain motor neuron differentiation by the homeobox gene Phox2b, Development 127 (2000) 1349-1358.

[3] J. Amiel, B. Laudier, T. Attié-Bitach, H. Trang, L. de Pontual, B. Gener, D. Trochet, H. Etchevers, P. Ray, M. Simonneau, M. Vekemans, A. Munnich, C. Gaultier, S. Lyonnet, Polyalanine expansion and frameshift mutations of the paired-like homeobox gene PHOX2B in congenital central hypoventilation syndrome, Nat Genet 33 (2003) 459-461.

[4] D.E. Weese-Mayer, E.M. Berry-Kravis, I. Ceccherini, T.G. Keens, D.A. Loghmanee, H. Trang, A.C.C.H.S. Subcommittee, An official ATS clinical policy statement: Congenital central hypoventilation syndrome: genetic basis, diagnosis, and management, Am J Respir Crit Care Med 181 (2010) 626-644.

[5] D.E. Weese-Mayer, E.M. Berry-Kravis, L. Zhou, B.S. Maher, J.M. Silvestri, M.E. Curran, M.L. Marazita, Idiopathic congenital central hypoventilation syndrome: analysis of genes pertinent to early autonomic nervous system embryologic development and identification of mutations in PHOX2b, Am J Med Genet A 123A (2003) 267-278.

[6] E.M. Berry-Kravis, L. Zhou, C.M. Rand, D.E. Weese-Mayer, Congenital central hypoventilation syndrome: PHOX2B mutations and phenotype, Am J Respir Crit Care Med 174 (2006) 1139-1144.

[7] T. Bachetti, I. Matera, S. Borghini, M. Di Duca, R. Ravazzolo, I. Ceccherini, Distinct pathogenetic mechanisms for PHOX2B associated polyalanine expansions and frameshift mutations in congenital central hypoventilation syndrome, Hum Mol Genet 14 (2005) 18151824.

[8] I. Matera, T. Bachetti, F. Puppo, M. Di Duca, F. Morandi, G.M. Casiraghi, M.R. Cilio, R. Hennekam, R. Hofstra, J.G. Schöber, R. Ravazzolo, G. Ottonello, I. Ceccherini, PHOX2B mutations and polyalanine expansions correlate with the severity of the respiratory phenotype and associated symptoms in both congenital and late onset Central Hypoventilation syndrome, J Med Genet 41 (2004) 373-380.

[9] C.M. Rand, M.S. Carroll, D.E. Weese-Mayer, Congenital central hypoventilation syndrome: a neurocristopathy with disordered respiratory control and autonomic regulation, Clin Chest Med 35 (2014) 535-545.

[10] D. Trochet, L.M. O'Brien, D. Gozal, H. Trang, A. Nordenskjöld, B. Laudier, P.J. Svensson, S. Uhrig, T. Cole, S. Niemann, A. Munnich, C. Gaultier, S. Lyonnet, J. Amiel, PHOX2B genotype allows for prediction of tumor risk in congenital central hypoventilation syndrome, Am J Hum Genet 76 (2005) 421-426.

[11] D. Trochet, L. de Pontual, C. Straus, D. Gozal, H. Trang, P. Landrieu, A. Munnich, S. Lyonnet, C. Gaultier, J. Amiel, PHOX2B germline and somatic mutations in late-onset central hypoventilation syndrome, Am J Respir Crit Care Med 177 (2008) 906-911.

[12] L.J. Jennings, M. Yu, C.M. Rand, N. Kravis, E.M. Berry-Kravis, P.P. Patwari, D.E. WeeseMayer, Variable human phenotype associated with novel deletions of the PHOX2B gene, Pediatr Pulmonol 47 (2012) 153-161.

[13] S. Di Lascio, R. Benfante, E. Di Zanni, S. Cardani, A. Adamo, D. Fornasari, I. Ceccherini, T. Bachetti, Structural and functional differences in PHOX2B frameshift mutations underlie isolated or syndromic congenital central hypoventilation syndrome, Hum Mutat 39 (2018) 219-236.

[14] C. Straus, H. Trang, M.H. Becquemin, P. Touraine, T. Similowski, Chemosensitivity recovery in Ondine's curse syndrome under treatment with desogestrel, Respir Physiol Neurobiol 171 (2010) 171-174. 
[15] F. Joubert, A.S. Perrin-Terrin, E. Verkaeren, P. Cardot, M.N. Fiamma, A. Frugière, I. Rivals, T. Similowski, C. Straus, L. Bodineau, Desogestrel enhances ventilation in ondine patients: Animal data involving serotoninergic systems, Neuropharmacology 107 (2016) 339-350.

[16] E. Shahar, S. Redline, T. Young, L.L. Boland, C.M. Baldwin, F.J. Nieto, G.T. O'Connor, D.M. Rapoport, J.A. Robbins, Hormone replacement therapy and sleep-disordered breathing, Am J Respir Crit Care Med 167 (2003) 1186-1192.

[17] M. Behan, J.M. Wenninger, Sex steroidal hormones and respiratory control, Respir Physiol Neurobiol 164 (2008) 213-221.

[18] R. Boukari, S. Laouafa, A. Ribon-Demars, A. Bairam, V. Joseph, Ovarian steroids act as respiratory stimulant and antioxidant against the causes and consequences of sleep-apnea in women, Respir Physiol Neurobiol 239 (2017) 46-54.

[19] F. Marcouiller, R. Boukari, S. Laouafa, R. Lavoie, V. Joseph, The nuclear progesterone receptor reduces post-sigh apneas during sleep and increases the ventilatory response to hypercapnia in adult female mice, PLoS One 9 (2014) e100421.

[20] C. Loiseau, D. Osinski, F. Joubert, C. Straus, T. Similowski, L. Bodineau, The progestin etonogestrel enhances the respiratory response to metabolic acidosis in newborn rats. Evidence for a mechanism involving supramedullary structures, Neurosci Lett 567 (2014) 63-67.

[21] B.J. Kang, D.A. Chang, D.D. Mackay, G.H. West, T.S. Moreira, A.C. Takakura, J.M. Gwilt, P.G. Guyenet, R.L. Stornetta, Central nervous system distribution of the transcription factor Phox 2b in the adult rat, J Comp Neurol 503 (2007) 627-641.

[22] P.S. Quadros, L.J. Schlueter, C.K. Wagner, Distribution of progesterone receptor immunoreactivity in the midbrain and hindbrain of postnatal rats, Dev Neurobiol 68 (2008) 1378-1390.

[23] G. Grandi, A. Cagnacci, A. Volpe, Pharmacokinetic evaluation of desogestrel as a female contraceptive, Expert Opin Drug Metab Toxicol 10 (2014) 1-10.

[24] A. Flora, H. Lucchetti, R. Benfante, C. Goridis, F. Clementi, D. Fornasari, Sp proteins and Phox $2 b$ regulate the expression of the human Phox2a gene, J Neurosci 21 (2001) 70377045.

[25] S. Di Lascio, T. Bachetti, E. Saba, I. Ceccherini, R. Benfante, D. Fornasari, Transcriptional dysregulation and impairment of PHOX2B auto-regulatory mechanism induced by polyalanine expansion mutations associated with congenital central hypoventilation syndrome, Neurobiology of Disease 50 (2013) 187-200.

[26] S. Borghini, T. Bachetti, M. Fava, M. Di Duca, F. Cargnin, D. Fornasari, R. Ravazzolo, I. Ceccherini, The TLX2 homeobox gene is a transcriptional target of PHOX2B in neuralcrest-derived cells, Biochem J 395 (2006) 355-361.

[27] R. Benfante, R.A. Antonini, N. Kuster, J. Schuderer, C. Maercker, F. Adlkofer, F. Clementi, D. Fornasari, The expression of PHOX2A, PHOX2B and of their target gene dopaminebeta-hydroxylase (DbetaH) is not modified by exposure to extremely-low-frequency electromagnetic field (ELF-EMF) in a human neuronal model, Toxicol In Vitro 22 (2008) 1489-1495.

[28] D.M. Cork, T.W. Lennard, A.J. Tyson-Capper, Alternative splicing and the progesterone receptor in breast cancer, Breast Cancer Res 10 (2008) 207.

[29] T. Bachetti, E. Di Zanni, R. Ravazzolo, I. Ceccherini, miR-204 mediates post-transcriptional down-regulation of PHOX2B gene expression in neuroblastoma cells, Biochim Biophys Acta 1849 (2015) 1057-1065.

[30] G. Haimovich, D.A. Medina, S.Z. Causse, M. Garber, G. Millán-Zambrano, O. Barkai, S. Chávez, J.E. Pérez-Ortín, X. Darzacq, M. Choder, Gene expression is circular: factors for mRNA degradation also foster mRNA synthesis, Cell 153 (2013) 1000-1011. 
[31] V. Boeva, C. Louis-Brennetot, A. Peltier, S. Durand, C. Pierre-Eugène, V. Raynal, H.C. Etchevers, S. Thomas, A. Lermine, E. Daudigeos-Dubus, B. Geoerger, M.F. Orth, T.G.P. Grünewald, E. Diaz, B. Ducos, D. Surdez, A.M. Carcaboso, I. Medvedeva, T. Deller, V. Combaret, E. Lapouble, G. Pierron, S. Grossetête-Lalami, S. Baulande, G. Schleiermacher, E. Barillot, H. Rohrer, O. Delattre, I. Janoueix-Lerosey, Heterogeneity of neuroblastoma cell identity defined by transcriptional circuitries, Nat Genet 49 (2017) 1408-1413.

[32] P.J. Jensik, L.A. Arbogast, Differential and interactive effects of ligand-bound progesterone receptor A and B isoforms on tyrosine hydroxylase promoter activity, J Neuroendocrinol 23 (2011) 915-925.

[33] R.M. Fernández, Y. Mathieu, B. Luzón-Toro, R. Núñez-Torres, A. González-Meneses, G. Antiñolo, J. Amiel, S. Borrego, Contributions of PHOX2B in the pathogenesis of Hirschsprung disease, PLoS One 8 (2013) e54043.

[34] V. Dubreuil, N. Ramanantsoa, D. Trochet, V. Vaubourg, J. Amiel, J. Gallego, J.F. Brunet, C. Goridis, A human mutation in Phox $2 b$ causes lack of $\mathrm{CO} 2$ chemosensitivity, fatal central apnea, and specific loss of parafacial neurons, Proc Natl Acad Sci U S A 105 (2008) 10671072 .

[35] E. Durand, S. Dauger, A. Pattyn, C. Gaultier, C. Goridis, J. Gallego, Sleep-disordered breathing in newborn mice heterozygous for the transcription factor Phox $2 b$, Am J Respir Crit Care Med 172 (2005) 238-243.

[36] N. Ramanantsoa, M.R. Hirsch, M. Thoby-Brisson, V. Dubreuil, J. Bouvier, P.L. Ruffault, B. Matrot, G. Fortin, J.F. Brunet, J. Gallego, C. Goridis, Breathing without $\mathrm{CO}(2)$ chemosensitivity in conditional Phox2b mutants, J Neurosci 31 (2011) 12880-12888.

[37] N. Ramanantsoa, B. Matrot, G. Vardon, A.M. Lajard, N. Voituron, S. Dauger, A. Denjean, G. Hilaire, J. Gallego, Impaired ventilatory and thermoregulatory responses to hypoxic stress in newborn phox 2b heterozygous knock-out mice, Front Physiol 2 (2011) 61.

[38] H. Nobuta, M.R. Cilio, O. Danhaive, H.H. Tsai, S. Tupal, S.M. Chang, A. Murnen, F. Kreitzer, V. Bravo, C. Czeisler, H.N. Gokozan, P. Gygli, S. Bush, D.E. Weese-Mayer, B. Conklin, S.P. Yee, E.J. Huang, P.A. Gray, D. Rowitch, J.J. Otero, Dysregulation of locus coeruleus development in congenital central hypoventilation syndrome, Acta Neuropathol 130 (2015) 171-183.

[39] M. Nagashimada, H. Ohta, C. Li, K. Nakao, T. Uesaka, J.F. Brunet, J. Amiel, D. Trochet, T. Wakayama, H. Enomoto, Autonomic neurocristopathy-associated mutations in PHOX2B dysregulate Sox 10 expression, J Clin Invest 122 (2012) 3145-3158.

[40] E. Rudzinski, R.P. Kapur, PHOX2B immunolocalization of the candidate human retrotrapezoid nucleus, Pediatr Dev Pathol 13 (2010) 291-299.

[41] Y. Fan, J. Huang, M. Duffourc, R.L. Kao, G.A. Ordway, R. Huang, M.Y. Zhu, Transcription factor Phox2 upregulates expression of norepinephrine transporter and dopamine $\beta$ hydroxylase in adult rat brains, Neuroscience 192 (2011) 37-53.

[42] M.S. Carroll, P.P. Patwari, A.S. Kenny, C.D. Brogadir, T.M. Stewart, D.E. Weese-Mayer, Residual chemosensitivity to ventilatory challenges in genotyped congenital central hypoventilation syndrome, J Appl Physiol (1985) 116 (2014) 439-450.

[43] P.G. Guyenet, R.L. Stornetta, S.B. Abbott, S.D. Depuy, R. Kanbar, The retrotrapezoid nucleus and breathing, Adv Exp Med Biol 758 (2012) 115-122.

[44] R.L. Stornetta, T.S. Moreira, A.C. Takakura, B.J. Kang, D.A. Chang, G.H. West, J.F. Brunet, D.K. Mulkey, D.A. Bayliss, P.G. Guyenet, Expression of Phox2b by brainstem neurons involved in chemosensory integration in the adult rat, J Neurosci 26 (2006) 1030510314.

[45] A.C. Takakura, T.S. Moreira, E. Colombari, G.H. West, R.L. Stornetta, P.G. Guyenet, Peripheral chemoreceptor inputs to retrotrapezoid nucleus (RTN) CO2-sensitive neurons in rats, J Physiol 572 (2006) 503-523. 
[46] O. Pascual, M.P. Morin-Surun, B. Barna, M. Denavit-Saubié, J.M. Pequignot, J. Champagnat, Progesterone reverses the neuronal responses to hypoxia in rat nucleus tractus solitarius in vitro, J Physiol 544 (2002) 511-520.

[47] A. Li, E. Nattie, Catecholamine neurones in rats modulate sleep, breathing, central chemoreception and breathing variability, J Physiol 570 (2006) 385-396.

[48] S. Zanella, J.C. Roux, J.C. Viemari, G. Hilaire, Possible modulation of the mouse respiratory rhythm generator by A1/C1 neurones, Respir Physiol Neurobiol 153 (2006) 126138. 


\section{FIGURE LEGENDS}

Figure 1. Effects of 3-KDG on the expression of PHOX2B protein and its transcriptional activity on the TLX2 and DBH target promoters

$A$ and $B$ ) Western blot analysis and quantification of the effect of 3-KDG on PHOX2B endogenous protein in SK-N-BE(2)C cells. A) Total protein extracts of SK-N-BE(2)C cells transfected with the PGR expression vector (lanes 3 and 4) or the empty vector pCDNA3 (lanes 1 and 2), and treated with 3-KDG for 48 hours (lanes 2 and 4). Extracts of the IMR32 (lane 5) and T47D cell lines (lane 6) were respectively used as positive controls of PHOX2B and PGR expression. B) Relative quantification of PHOX2B protein in untreated (black and white bars) and 3-KDG treated cells (hatched bars). The results are the mean PHOX2B values ( \pm SD, error bars) normalised to that of $\beta$ tubulin (TUB) in two independent experiments, and are expressed as fold-induction over untreated cells $(=1) .{ }^{*} \mathrm{p}<0.05$, significant differences in PHOX2B levels between the treated (white hatched bar) and untreated (white bar) cells transfected with the hPGR vector (Student's $t$ test). $C$ and $D$ ) Luciferase assay. The bars indicate the transcriptional activity of reporter constructs driven by the $T L X 2$ (C, right) and $D B H$ promoter (D, right) upon the co-transfection of the PGR expression vector in SK-N-BE(2)C cells treated with $1 \mathrm{nM} 3-\mathrm{KDG}$ (hatched bars) or $3 \mathrm{nM}$ progesterone (crosshatched bars) for 48 hours. The empty vectors pGL3b (C, left) and pGL4b (D, left) were used as negative controls (grey bars). The results are the mean values \pm SD (error bars) of the transcriptional activity of the constructs in at least five experiments performed in duplicate, and are expressed as RLU normalised to that of Renilla. ***p<0.001, significant differences in activity between the treated and untreated cells transfected with $T L X 2$ or $D B H$ promoters (one-way ANOVA, Tukey's test).

Figure 2. Effects of 3-KDG on endogenous PHOX2B protein in stable SK-N-BE(2)C hPGR clones.

A) Representative Western blot of endogenous PHOX2B in SK-N-BE(2)C cells stably overexpressing hPGR (clones 5.8 and 6.30, lanes 5 to 12) and untransfected SK-N-BE(2)C cells (lanes 1 to 4 ) after treatment with $1 \mathrm{nM} 3-\mathrm{KDG}$ for eight, 24 or 48 hours. IMR32 nuclear extract (IMR32 $\mathrm{NE}$, lane 13) and T47D (lane 14) were respectively used as positive and negative controls for PHOX2B. B) The bar chart shows the relative quantification of PHOX2B protein in native SK-N$\mathrm{BE}(2) \mathrm{C}$ cells (black bars), SK-N-BE(2)C clone 5.8 cells (grey bars) and SK-N-BE(2)C clone 6.30 cells (white bars) after 3-KDG treatment (hatched bars). The data show the relative fold induction in the treated samples in relation to the untreated samples $(=1)$, and are expressed as the mean values ( $\pm \mathrm{SD}$, error bars) of the densitometry intensity of each lane normalised to $\beta$-tubulin (TUB) in at 
least three independent experiments. $* * * p<0.001$, $* * \mathrm{p}<0.01$ and $* \mathrm{p}<0.05$, significant differences in PHOX2B protein levels between treated and untreated (-) clones 5.8 and 6.30 (one-way ANOVA, Tukey's test).

\section{Figure 3. Effects of 3-KDG on PHOX2B target genes.}

A) Representative Western blots of PHOX2B target genes expression in stable SK-N-BE(2)C clones 5.8 (lanes 5-8) and cl. 6.30 (lanes 9-12), and native SK-N-BE(2)C cells (lanes 1-4) after treatment with $1 \mathrm{nM} 3-\mathrm{KDG}$ for eight, 24 or 48 hours. The DBH and TFAP2A signal were normalised to that of $\beta$-tubulin (TUB). $B$, and $C$ ) The bar charts show the relative quantification of DBH (B) and TFAP2A (AP-2 alpha, C) protein levels in native SK-N-BE(2)C cells (black bars), clone 5.8 (grey bars) and clone 6.30 cells (white bars) after 3-KDG treatment (hatched bars). The data indicate the relative fold induction in the treated samples in relation to the untreated samples $(=1)$, and are expressed as the mean values $\pm \mathrm{SD}$ (error bars) of at least three independent experiments. $* * \mathrm{p}<0.01$ and $* \mathrm{p}<0.05$, significant differences in DBH (B) and TFAP2A (C) protein levels between the treated and untreated (-) cells (one-way ANOVA, Tukey's test).

\section{Figure 4. 3-KDG affects $P H O X 2 B$ mRNA stability}

A) Time course qPCR analysis of endogenous $P H O X 2 B$ mRNA expression normalised to that of the GAPDH gene in native SK-N-BE(2)C (black bars) and clone 5.8 cells (grey bars) treated with $1 \mathrm{nM}$ 3-KDG (hatched bars) for the indicated times. The bars indicate the relative fold induction in the treated samples in relation to the untreated samples $(=1)$ calculated using the $2^{-\Delta \Delta \mathrm{CT}}$ method, and are expressed as the mean values \pm SD (error bars) of at least three independent experiments performed in triplicate. ${ }^{*} \mathrm{p}<0.05$, statistically significant differences in PHOX2B mRNA expression in SK-N$\mathrm{BE}(2) \mathrm{C}$ clone 5.8 cells, between the treated and untreated samples (one-way ANOVA, Tukey's test). $B$ ) The same experiment as in $A$ was performed for a shorter time. The bars represent the mean values $\pm \mathrm{SD}$ (error bars) of fold induction in comparison with the untreated sample (=1 grey bar) in a single representative experiment performed in triplicate. $* * * \mathrm{p}<0.001$, statistically significant differences between the treated and untreated samples (one-way ANOVA, Tukey's test). $C$ and $D$ ) PHOX2B mRNA decay determined by qPCR analysis. C) Top: schematic representation of the protocol. SK-N-BE(2)C clone 5.8 cells were pre-treated with $1 \mathrm{nM} 3-\mathrm{KDG}$ (graph solid line), or vehicle (DMSO; graph dashed line) for 24 hours before the addition of $75 \mu \mathrm{M}$ DRB for different times. D) Top: schematic representation of the protocol. SK-N-BE(2)C clone 5.8 cells were treated with $1 \mathrm{nM} 3$-KDG (solid line) or DMSO (dashed line) together with DRB $(75 \mu \mathrm{M})$ for different times. Data are represented as mean values \pm SD (error bars) of three (panel C) and two (panel D) independent experiments performed in triplicate, and normalised to the endogenous GAPDH gene. 
PHOX2B mRNA levels at each time point were compared to those in untreated cells (initial level, $\mathrm{T} 0=1$ in panel $\mathrm{C}$; or $=1$ in panel $\mathrm{D}$ ), and are expressed as fold induction calculated using the $2^{-\Delta \Delta \mathrm{CT}}$ method. Non-linear regression analysis was used to calculate one-phase exponential $P H O X 2 B$ mRNA decay (GraphPad Prism 5.0). ${ }^{* * *} \mathrm{p}<0.001$, ${ }^{* *} \mathrm{p}<0.01$ and $* \mathrm{p}<0.05$, statistically significant differences in PHOX2B mRNA levels between each time point and T0 (one-way ANOVA, Tukey's test). ${ }^{\#} \mathrm{p}<0.01$ and ${ }^{\#} \mathrm{p}<0.05$, statistically significant differences in $P H O X 2 B$ mRNA levels between treated and untreated cells after two and four hours of DRB treatment (Student's $t$ test).

\section{Figure 5. 3-KDG does not affect PHOX2B protein stability}

$A$ and $C$ ) Top: schematic representation of the protocol. Bottom: representative Western blots. A) SK-N-BE(2)C clone 5.8 cells were pre-treated with $1 \mu \mathrm{g} / \mathrm{mL}$ CHX for one hour (lane 3) and the treatment was continued with (lanes 4-7) or without $1 \mathrm{nM} 3-\mathrm{KDG}$ (lanes 8-11) for the indicated times. Lane 2: untreated cells. IMR32 nuclear extract (IMR32 NE, lane 1) was used as a positive control for PHOX2B. The PHOX2B signal was normalised to that of $\beta$-tubulin (TUB). $C$ ) SK-N$\mathrm{BE}(2) \mathrm{C}$ clone 5.8 cells were pre-treated with (lanes 2-7) or without (lanes 8-13) $1 \mathrm{nM} 3-\mathrm{KDG}$ for two hours before the addition of $1 \mu \mathrm{g} / \mathrm{mL}$ CHX. IMR32 nuclear extract (IMR32 NE, lane 1) was used as a positive control for PHOX2B. $B$ and $D$ ) Quantification. The graphs show the relative quantification of PHOX2B protein levels at each time point in comparison with T0 $(=1)$ : i.e. before the addition of DMSO/3-KDG (protocol A) or $\mathrm{CHX}$ (protocol $\mathrm{C}$ ) in the treated (solid line) and untreated samples (dashed line) expressed as the mean densitometry intensity values \pm SD (error bars) of each lane normalised to that of $\beta$-tubulin in two independent experiments. Non-linear regression analysis was used to calculate one-phase exponential decay (GraphPad Prism 5.0). 


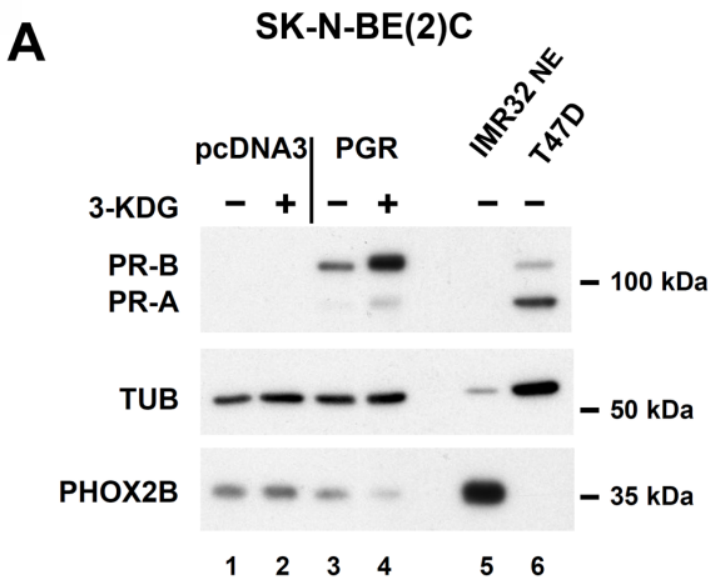

B

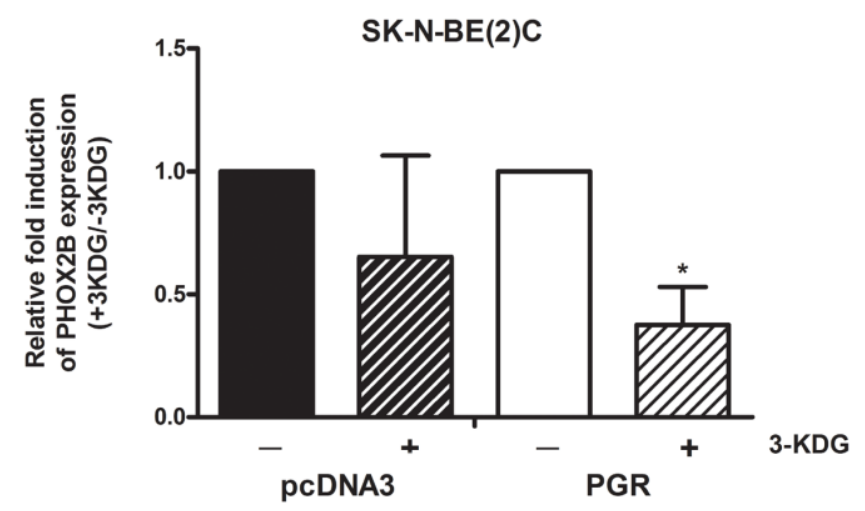

C

TLX2

D

DBH
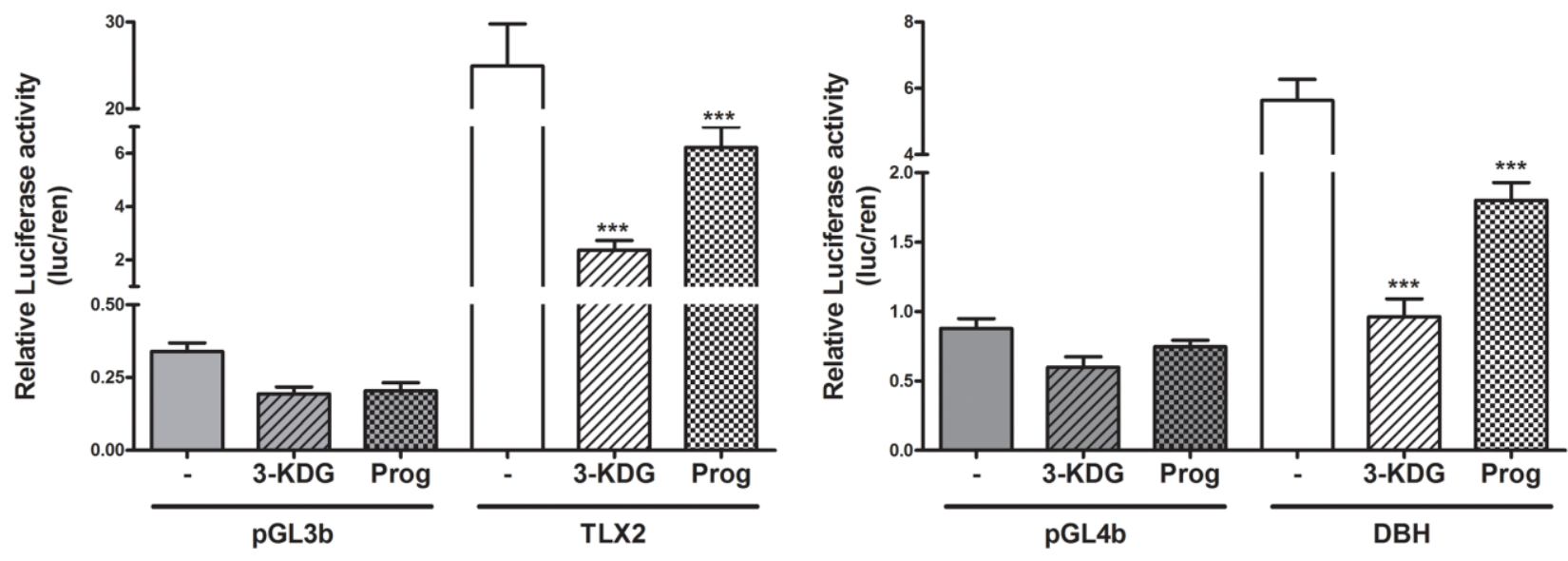

Fig. 1 
A

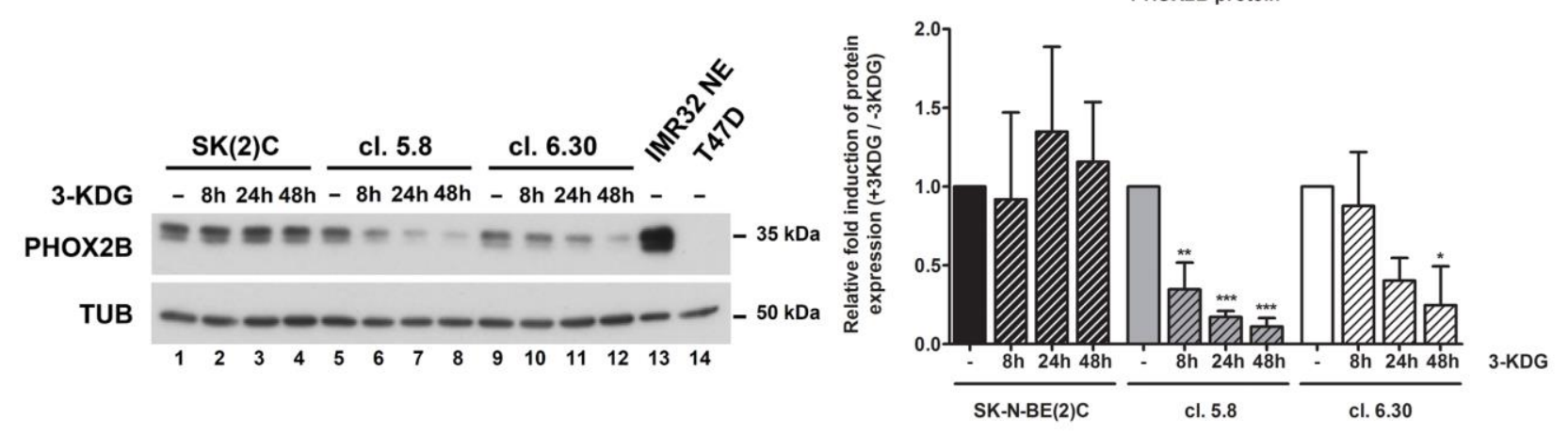

Fig. 2 

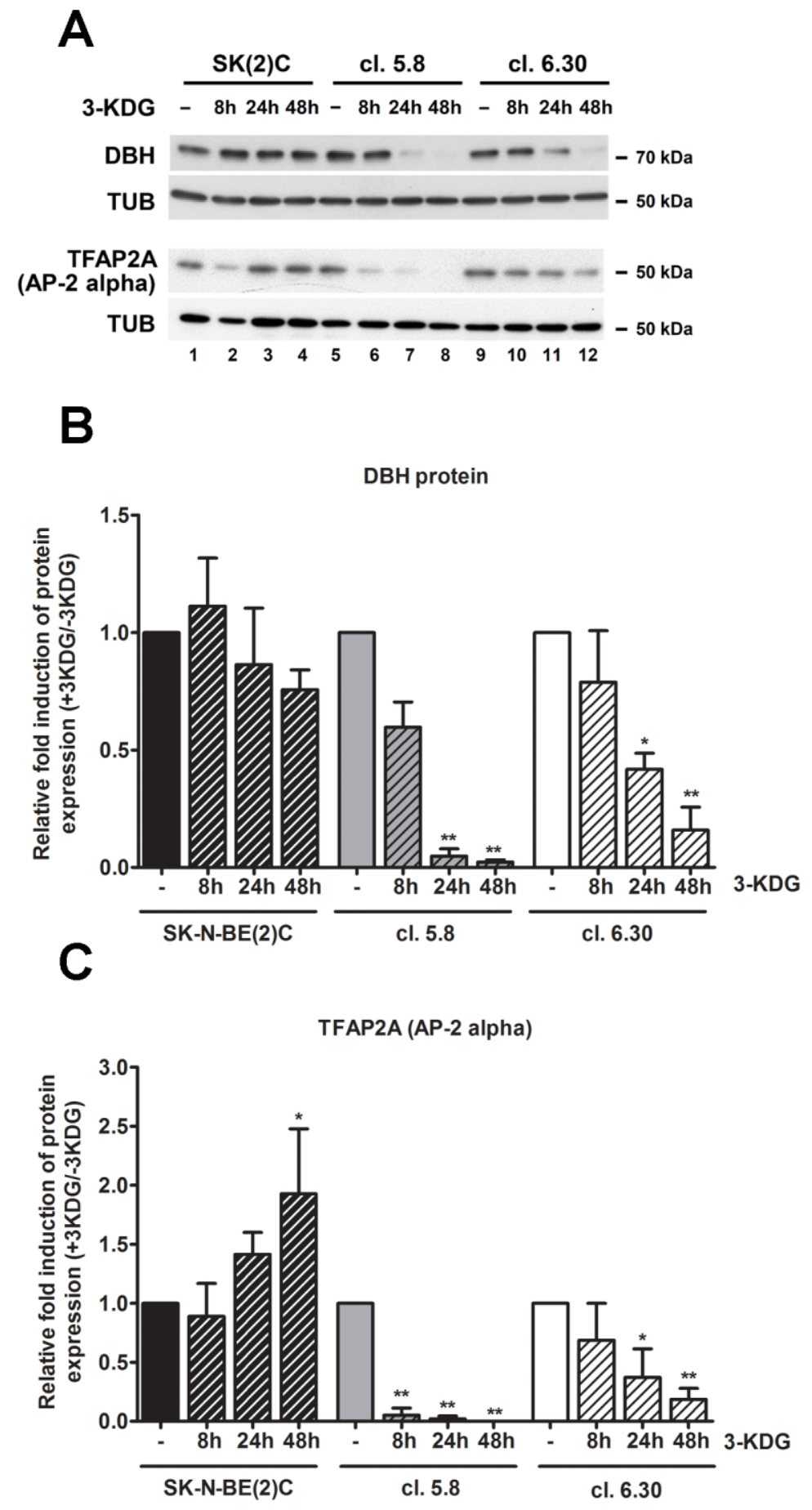

Fig. 3 
A

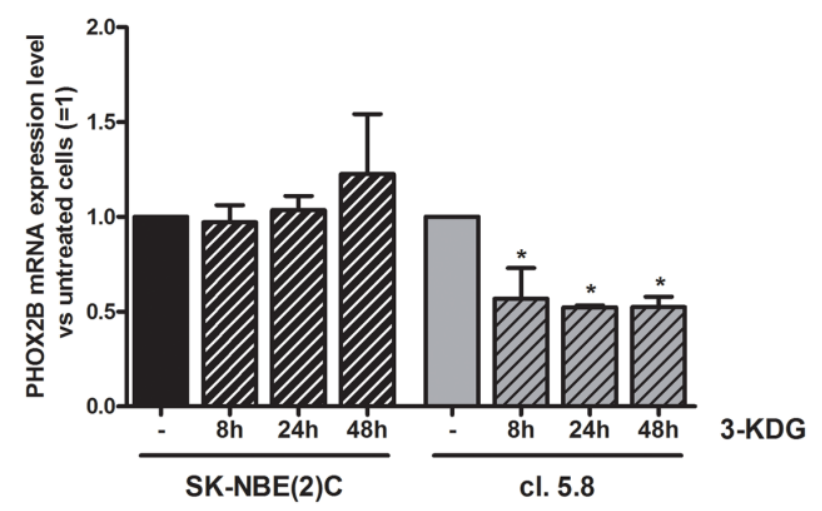

C
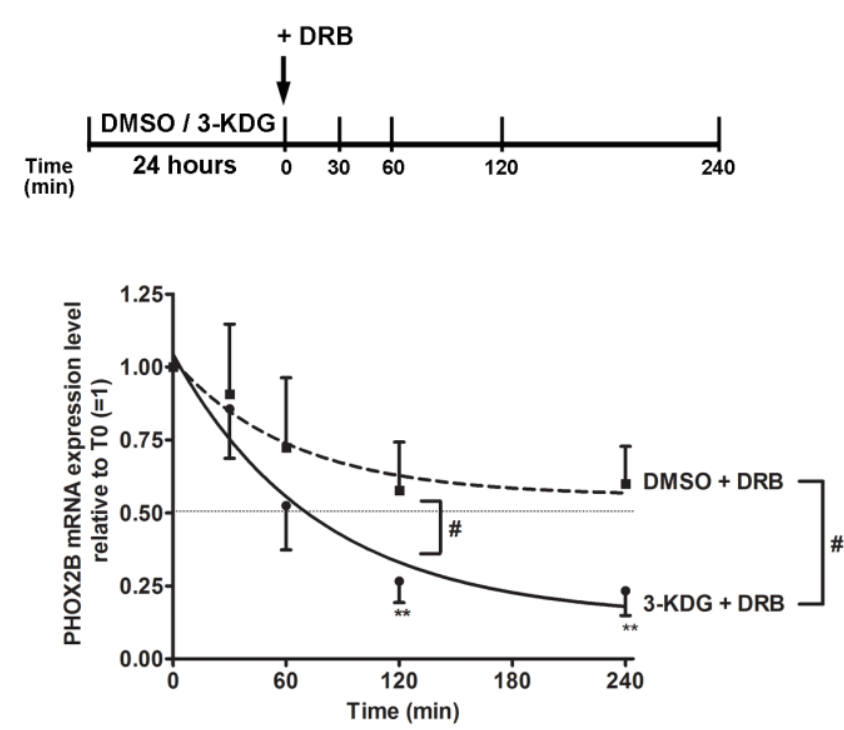

B

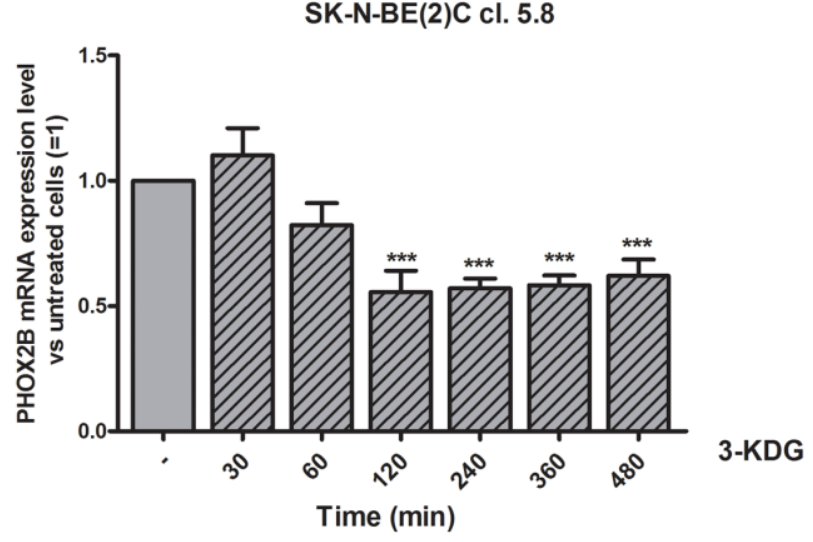

D


Fig. 4 

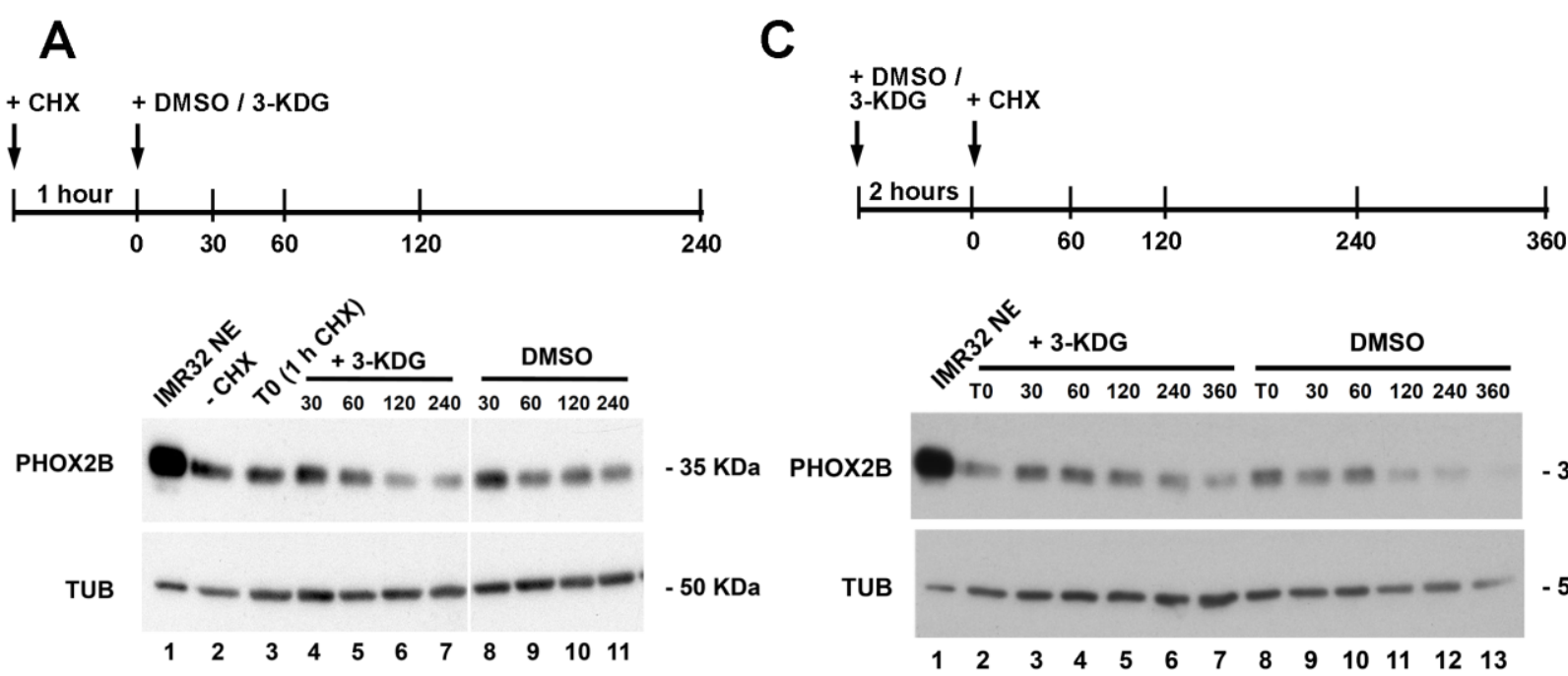

B

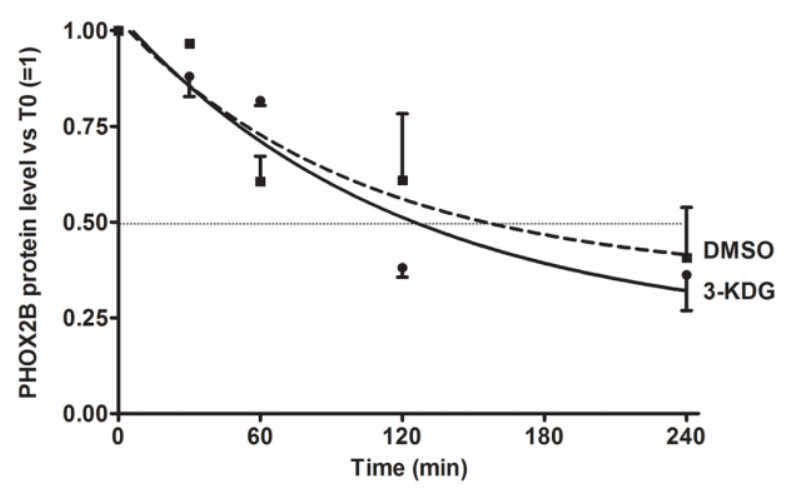

D

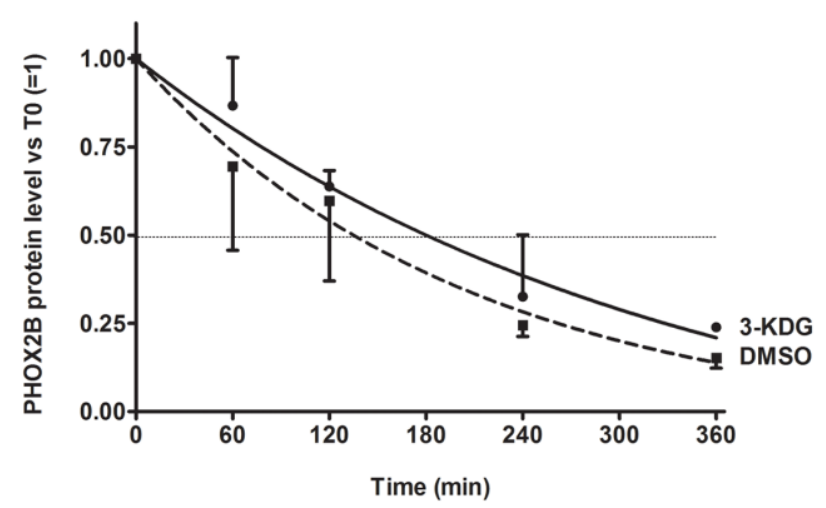

Fig. 5 